\title{
A INTEGRAÇÃO DAS TECNOLOGIAS DE INFORMAÇÃO E COMUNICAÇÃ̃ NA ESCOLA: O PROJETO POLÍTICO PEDAGÓGICO NESSE CONTEXTO
}

\author{
Márcia Ferreira de CASTRO ${ }^{1}$ \\ Sebastião de Souza LEMES $^{2}$
}

RESUMO: O presente trabalho tem como objetivo analisar as possibilidades de integração das novas tecnologias de informação e comunicação (TIC) no processo de ensino-aprendizagem em uma escola de Ensino Fundamental da Rede Municipal de Araraquara. Trata-se de uma pesquisa fundamentada numa abordagem qualitativa, que tem como estratégia o Estudo de Caso. Fez-se uma análise das Diretrizes Curriculares e do Projeto Político Pedagógico (PPP) da escola selecionada, com o intuito de verificar como a escola aborda o tema do uso das novas tecnologias no processo educativo. Pela análise feita das Diretrizes Curriculares e do Projeto Político Pedagógico constatamos que a escola estudada tem uma preocupação em fazer uso das TIC no processo de ensino e aprendizagem, o que caracteriza uma conscientização da importância das tecnologias na educação, porém não descreve formas de integrá-las curricularmente. A integração das novas tecnologias no currículo exige uma reflexão sistemática acerca de seus objetivos, de suas técnicas e dos conteúdos escolhidos. Não é somente trabalhar com as novas tecnologias visando à inclusão digital dos alunos, mas é preciso que a escola as integre nas atividades curriculares, ou seja, integrá-las ao processo de ensino e aprendizagem. Hoje as TIC se configuram em uma nova forma de linguagem, essencial para a representação do conhecimento e, nesse caso, sua presença no currículo escolar é fundamental.

PALAVRAS-CHAVE: Tecnologias de Informação e Comunicação. Ensino. Aprendizagem. Currículo.

\section{Introdução}

O desenvolvimento ocorrido a partir de meados do século XX no campo das telecomunicações e da informática gerou mudanças profundas na sociedade a uma velocidade nunca vista antes na história da humanidade. As novas tecnologias de informação e comunicação (TIC) proporcionam novas formas de trabalhar, interagir, divertir-se, comunicar-se e aprender. Porém, as mudanças ocorrem não apenas pelo uso de aparatos tecnológicos, mas "podemos afirmar que vamos avançando para uma sociedade em rede que busca formas de organização mais flexíveis, horizontais e

\footnotetext{
${ }^{1}$ Mestranda em Educação Escolar. UNESP - Universidade Estadual Paulista. Faculdade de Ciências e Letras - Pós-Graduação em Educação Escolar. Araraquara - SP - Brasil. 14800-901 marciacasfer@yahoo.com.br.

${ }^{2}$ Docente. UNESP - Universidade Estadual Paulista. Faculdade de Ciências e Letras - Departamento de Ciências da Educação. Araraquara - SP - Brasil.14800-901 - ss.lemes2@gmail.com.
} 
eficientes", na qual a informação e o conhecimento são disponibilizados em sistemas mais abertos, acessíveis e democráticos (MARCELO, 2013, p.25).

Assim, termos como Sociedade da Informação, do Conhecimento e da Aprendizagem emergem para caracterizar a sociedade atual ao mesmo tempo em que colocam em evidência os elementos essenciais para seu funcionamento, ou seja, informação e o conhecimento são os insumos mais importantes na sociedade contemporânea e a capacidade de aprendizagem permanente a condição necessária e indispensável para o seu desenvolvimento social, econômico e cultural (CASTELLS, 1999; POZO, 2004; COLL; ILLERA, 2010).

Neste contexto, um dos maiores desafios dos sistemas educacionais é definir como educar nesta nova sociedade que exige não apenas que cada vez mais pessoas aprendam, "mas que aprendam de outra maneira, no âmbito de uma nova cultura da aprendizagem, de uma nova forma de conceber e gerir o conhecimento, seja da perspectiva cognitiva ou social” (POZO, 2004, p.1).

Para Pozo (2004), na sociedade da aprendizagem é preciso apropriar-se de novas formas de aprender e relacionar-se com o conhecimento. Pozo (2004) diz que a função básica da aprendizagem é interiorizar ou incorporar a cultura e passar a fazer parte dela. Para este autor é pela aprendizagem que incorporamos a cultura, que por sua vez, traz novas formas de aprendizagem. Corroborando com essa perspectiva, Lemes (2013, p.249) coloca que as

[...] atividades de aprendizagem devem ser compreendidas no contexto das demandas sociais que as geram. Há uma necessária evolução do aprender e das formas culturais, através das quais se processa a aprendizagem. Com isso, torna-se absolutamente necessário se conhecer as novas demandas da sociedade e da(s) cultura(s) para a escola, tanto para que se tenha seu entendimento, como para que se posicione criticamente frente a essas.

É nesse cenário que se coloca a questão da integração das tecnologias de informação e comunicação (TIC) na educação. Hoje, as novas formas de aprender e relacionar-se com o conhecimento passam, inegavelmente, pela apropriação das novas tecnologias de informação e comunicação, o que reforça o debate acerca do papel da escola em um mundo informatizado. As discussões apresentadas sobre o uso das TIC 
nas escolas vêm, já há algum tempo, sendo sustentadas pela ideia da escola se preparar para uma educação condizente com as necessidades da sociedade do século XXI.

Hoje, as tecnologias estão presentes nas escolas ${ }^{3}$, porém esta presença deve ir além da perspectiva de modernização do sistema e da necessidade de aprender a dominar um novo instrumento, ela pressupõe uma nova cultura da aprendizagem, que só é possível mediante "mudança de mentalidade, uma mudança nas concepções profundamente arraigadas de uns e de outros sobre a aprendizagem e o ensino" (POZO; PEREZ ECHEVERÍA, 2001 apud POZO, 2004, p.36).

José Gimeno Sacristán (2002, p.30) coloca que "uma nova sociedade conectada em rede está emergindo como conseqüência de fenômenos econômicos, políticos e culturais globalizadores que incidem sobre a educação e exigem dela uma resposta". Além disso, Gimeno Sacristán (2002, p.24) considera que "um projeto para a educação significa refletir, discutir e decidir sobre seus conteúdos e suas maneiras de inserir os sujeitos na cultura” (GIMENO SACRISTÀN, 1994 apud LEMES; RIBEIRO, 2010, p.347).

É no contexto sócio-cultural que as produções tecnológicas se inserem. Segundo Lévy (1999) há uma relação intrínseca entre técnica, cultura e sociedade na medida em que a tecnologia é produto de uma sociedade e de uma cultura. Para este autor, não é possível separar os homens de sua produção material. Uma sociedade é condicionada por suas técnicas, ou seja, a técnica abre possibilidades, ou cria condições, para o desenvolvimento humano. Sem a sua presença, algumas opções culturais e sociais não poderiam ser pensadas.

Segundo Lévy (1999), com o desenvolvimento das tecnologias as fundações culturais que comandam nossa apreensão do real mudam completamente, pois o inconsciente intelectual é permeado por coisas técnicas. A oralidade, a escrita, a impressão, as instituições e a informática são técnicas desenvolvidas historicamente e se articulam com os gêneros do conhecimento.

O autor desenvolve, então, o conceito de tecnologias intelectuais, por entender que não se tratam de simples instrumentos, mas podem ser consideradas como ferramentas de pensamento no sentido em que, ao se articularem com o sistema

\footnotetext{
3 Segundo os dados divulgados pelo Censo Escolar 2012, 45,8\% das escolas públicas de Ensino Fundamental têm acesso à Internet e 48,6\% têm laboratório de informática. No Ensino Médio, o percentual é bem maior, 93\% das escolas têm acesso à internet e 92,4\% possuem laboratório de informática.
} 
cognitivo, ajudam na constituição cognitiva e subjetiva dos indivíduos (LÉVY, 1999). Na perspectiva deste autor (LÉVY, 1993, p.7), “escrita, leitura, visão, audição, criação, aprendizagem são capturados por uma informática cada vez mais avançada”.

Vivemos o limiar de uma autêntica cultura digital (COSTA, 2003), no qual as novas tecnologias estão cada vez mais presentes no cotidiano das crianças e jovens, portanto, fazer um planejamento pedagógico dos usos desses meios é imprescindível nas instituições escolares. Educar no âmbito desta cultura "supõe ensinar e aprender a participar eficazmente nas práticas sociais e culturais mediadas de uma ou de outra maneira pelas tecnologias digitais" (COLL; ILLERA, 2010, p.307).

Para que a escola possa de fato abrir caminho para uma inovação pedagógica e didática, rumo a novos arranjos no processo de ensino e aprendizagem que reflitam as necessidades formativas da sociedade atual, é preciso que se pense a integração das novas tecnologias no âmbito do currículo escolar, pois "[...] é o conjunto do currículo que deve ser revisado a partir do referencial proporcionado pelas práticas sociais e culturais próprias da sociedade da informação, da leitura ética e ideológica que se faça delas e das necessidades formativas das pessoas neste novo cenário" (COLL; ILLERA, 2010, p.307).

Diante disso, considera-se necessário esclarecer o significado de integração das TIC na educação escolar. No contexto deste trabalho, adota-se o conceito de integração proposto por Sánchez (2002), no qual define que integrar as TIC “é torná-las parte do currículo, relacionando-as harmonicamente com os demais componentes do currículo. É utilizá-las como parte integral do currículo e não como um apêndice, não como um recurso periférico".

Assim, este trabalho tem como foco o planejamento da escola para integração das tecnologias de informação e comunicação no processo de ensino e aprendizagem. Professores, coordenadores e gestores têm a responsabilidade de definir a utilização das novas tecnologias na educação, pois é fundamental que "saibam claramente o que se deseja com os computadores e a informática na educação, ou seja, quais são as suas finalidades" (GENTILINI, 2013, p.49).

Para Vieira (2007, p.23) a inserção das novas tecnologias na escola passa também "pela própria organização da instituição escolar e as relações de outros atores envolvidos no processo educativo: coordenador pedagógico, orientador, vice-diretor, 
diretor, enfim a equipe que irá organizar e coordenar os processos pedagógicos da escola".

A legislação educacional ${ }^{4}$ vigente prevê que é responsabilidade da escola elaborar o seu Projeto Pedagógico (PP) e Projeto Curricular (PC). Nesse sentido, compete à equipe pedagógica da escola, entendida no âmbito deste trabalho como os professores, aos coordenadores pedagógicos e gestores, planejar de forma participativa as ações educativas. Para tanto, deve-se considerar, segundo Veiga (1998), os pressupostos filosófico-sociológico, epistemológico e didático- metodológico na elaboração desses projetos.

Assim, de acordo com Veiga (1998, p.25) a escola precisa ter clareza quanto ao contexto sociopolítico, econômico e cultural no qual está inserida, qual o estado do conhecimento nesse contexto e a escolha dos procedimentos metodológicos e recursos didáticos que melhor atenda às necessidades de aprendizagem, pois

[...] a escola tem que pensar o que pretende, do ponto de vista político e pedagógico. Há um alvo por ser atingido pela escola: a produção e a socialização do conhecimento, das ciências, das letras, das artes, da política e da tecnologia, para que o aluno possa compreender a realidade socioeconômica, política e cultural, tornando-se capaz de participar do processo de construção da sociedade.

Vosgerau (2012) destaca a importância do papel de todos os agentes educativos na integração das TIC no ambiente escolar. Nesse sentido, compreender o processo de integração das TIC, sob a ótica da equipe pedagógica da escola, permite entender a forma como a escola se organiza para usar as TIC no processo de ensino e aprendizagem. Para tanto, é necessário direcionar o olhar para a compreensão dos processos que favoreçam a integração das TIC no interior da escola.

\section{Percurso do trabalho}

O tema central desta pesquisa é o processo de integração das TIC no ambiente escolar e, nesse sentido, vai ao encontro das idéias de Vosgerau (2012), nas quais dizem

\footnotetext{
${ }^{4}$ Lei no 9.394/96 (Lei de Diretrizes e Bases da Educação Nacional) prevê no artigo 12, inciso I, que "os estabelecimentos de ensino, respeitadas as normas comuns e as do seu sistema de ensino, terão a incumbência de elaborar e executar sua proposta pedagógica".
} 
que analisar a integração das TIC na escola baseada somente no trabalho pedagógico do professor é insuficiente, pois a integração das TIC vai além da sala de aula, passa pela infra-estrutura da escola, equipe gestora, conhecimento do aluno e documentos normativos. Nesse sentido, o objetivo do trabalho é analisar as possibilidades de integração das novas tecnologias de informação e comunicação no processo de ensinoaprendizagem.

Dada essa questão, essa pesquisa se propõe a realizar uma análise do processo de integração das TIC no contexto escolar a partir de uma abordagem qualitativa, que segundo Denzin e Lincoln (2005), esse tipo de pesquisa pressupõe uma abordagem naturalística, ou seja, o estudo das coisas em seus cenários naturais, tentando entender ou interpretar os fenômenos em termos dos significados que as pessoas a eles conferem.

$\mathrm{Na}$ perspectiva de realizar um estudo de campo que permita uma análise do fenômeno estudado, opta-se pelo estudo de caso como estratégia de pesquisa. Yin (2001) afirma que a estratégia do estudo de caso é apropriada pelas investigações em educação quando o pesquisador é confrontado com situações complexas, quando procura encontrar interações entre fatores relevantes, quando o objetivo é descrever ou analisar o fenômeno e quando pretende apreender a dinâmica do fenômeno, do programa ou do processo em estudo.

A pesquisa circunscreve-se na cidade de Araraquara, interior do Estado de São Paulo. Fez-se um levantamento das escolas da Rede Municipal de Araraquara com a intenção de selecionar a unidade de análise. É importante esclarecer que a rede municipal de Araraquara é composta por 14 (quatorze) unidades escolares de Ensino Fundamental, sendo que 4 (quatro) unidades atendem alunos dos anos iniciais (ciclos I e II) e 10 (dez) unidades atendem os três ciclos ( $1^{\circ}$ ao $9^{\circ}$ ano).

O critério de escolha da escola a ser estudada foi pautado pelo Projeto Político Pedagógico (PPP). Buscou-se selecionar a escola em que o PPP fizesse alusão ao uso das novas tecnologias de informação e comunicação no processo de ensinoaprendizagem. Das 14 (quatorze) unidades, selecionou-se as escolas com o ensino fundamental completo, ou seja, as 10 escolas que atendiam todos os ciclos. Dentre estas escolas, excluímos 3 (três) unidades por fazerem parte do Programa Escolas do Campo da Secretaria Municipal de Educação.

Foi consultado, então, o PPP das 7 (sete) escolas da rede municipal que oferecem ensino fundamental completo. Destas, apenas uma trouxe a problemática das 
novas tecnologias de informação e comunicação em seu Projeto Político Pedagógico. Esta escola está localizada em um bairro periférico da cidade de Araraquara e foi criada em 1986, sob a responsabilidade da Secretaria Estadual de Educação. A partir de 1999, com o convênio firmado entre Estado e Município, a escola passa a ser municipal. Atualmente, esta unidade escolar atende crianças e adolescentes de seis a quatorze anos no ensino fundamental e acima de 15 anos no EJA (Educação de Jovens e Adultos), totalizando aproximadamente 800 alunos.

É importante esclarecer, neste momento, que a Secretaria de Educação de Araraquara estabeleceu, em 2011, uma parceria com o Sistema SESI de ensino. As escolas municipais passaram a adotar a o material didático da rede escolar SESI para alunos e professores. A escola selecionada para o estudo foi também a única que procurou adequar seu Projeto Político Pedagógico à nova proposta de ensino.

Quanto aos procedimentos para a coleta de dados, Yin (2001) salienta que o estudo de caso tem a capacidade de lidar com uma ampla variedade de evidências: documentos, artefatos, entrevistas e observações. No âmbito desta pesquisa, os instrumentos para coleta de dados são análise dos documentos normativos da escola, entrevistas, questionário e observação direta.

Para a análise dos dados obtidos utilizaremos o modelo de avaliação da integração das TIC no contexto escolar proposto por Pasinato e Vosgerau (2011), no qual apresenta seis categorias de análise que permitem identificar o grau de integração das TIC no ambiente escolar. As seis categorias propostas por Pasinato e Vosgerau (2011) são: Não utilização, Familiarização, Conscientização, Implementação, Integração e Evolução. Em todas essas categorias são considerados o professor, o aluno, os recursos tecnológicos, a gestão escolar e os documentos normativos da escola.

\section{Resultados preliminares}

Primeiramente, ressaltamos que esta é uma pesquisa em andamento e consta de várias etapas de coleta de dados. Expomos aqui os resultados preliminares da primeira etapa, que se baseou na análise do Projeto Político Pedagógico (PPP) da escola selecionada, com o intuito de verificar como a escola aborda o tema do uso das novas tecnologias no processo educativo. 
A escola selecionada para o estudo adequou o seu PPP de acordo com Referenciais Curriculares da Rede Escolar SESI que, como já mencionado, balizam o currículo das escolas municipais de Araraquara. A concepção educacional do sistema SESI se fundamenta na tríade ensino, aprendizagem e pesquisa. De acordo com os Referenciais Curriculares da rede escolar SESI (SESI, 2003, p.69), o processo de ensino-aprendizagem se pauta na abordagem sócio-interacionista, que atribui ao processo educativo uma dimensão histórica e social. Nesta concepção as práticas pedagógicas do professor devem "criar condições para que haja uma interação entre o aluno, o objeto do conhecimento e o meio sociocultural".

Quanto à inserção das novas tecnologias no currículo, os Referenciais Curriculares da rede escolar SESI (SESI, 2003, p.18) propõem em seus objetivos "propiciar a todos os educandos os conhecimentos científicos, culturais e tecnológicos de qualidade, a fim de que se situem no mundo globalizado" e "estimular no educando a capacidade de conviver com os impactos das novas tecnologias, aliando teoria e prática, ressignificando os conhecimentos historicamente acumulados na perspectiva de aprender a aprender".

A partir de uma leitura atenta dos Referenciais Curriculares do SESI, notamos que sua proposta pedagógica exige uma postura autônoma do aluno no processo de aprendizagem e para isso destaca a importância da escola em buscar diferentes meios para incentivar os alunos a aprender. As tecnologias de informação e comunicação são tratadas como instrumentos que enriquecem e facilitam a aprendizagem dos alunos. Além disso, os Referenciais Curriculares do SESI dão ênfase nas atividades de pesquisa, que são vistas como grandes potencializadoras do desenvolvimento da autonomia dos alunos e, nesse sentido, as TIC cumprem um papel fundamental, por possibilitar maior acesso às informações e conhecimentos.

Quanto ao PPP da escola em estudo, a proposta pedagógica para o uso das TIC segue as diretrizes do sistema escolas SESI. Há uma intenção em aprofundar o uso das tecnologias no processo de ensino e aprendizagem. O PPP faz referência ao atual contexto social, político, econômico e cultural da sociedade hoje, e relaciona o papel da escola e das TIC nesse contexto: a escola deve ser o local para "[...] construir saberes que contribuam para o aluno saber atuar em sociedade de modo consciente e responsável e interagir com autonomia face as especificidades do mundo contemporâneo" (SESI, 2003, p.30). 
O PPP também ressalta a importância dos alunos dominarem as linguagens, os códigos e as tecnologias presentes na sociedade atual, pois são sistemas de signos convencionados pela coletividade. Além disso, o aluno precisa se conscientizar de que na contemporaneidade os avanços científicos e tecnológicos são cada vez mais velozes, "tornando o conhecimento cada vez mais provisório, fazendo-se necessário a interação de forma consciente com a tecnologia, uma vez que esta corrobora com as relações de comunicação e trânsito de informações" (SESI, 2003, p. 30). Assim, O PPP ressalta que é importante familiarizar o aluno com os produtos tecnológicos presentes na vida doméstica e social, além do que o currículo escolar deve ser elaborado e definido considerando a rápida difusão do conhecimento técnico-científico e o papel das tecnologias de informação e comunicação nesse processo.

\section{Considerações}

As TIC estão remodelando as formas de criar, armazenar e distribuir a informação e o conhecimento. Com isso, integrá-las aos currículos escolares nos parece um processo pelo qual as escolas deverão passar. No contexto de uma sociedade da informação e do conhecimento, a educação exige uma abordagem diferente em que o componente tecnológico não pode ser ignorado.

A integração das novas tecnologias no currículo exige uma reflexão sistemática acerca de seus objetivos, de suas técnicas e dos conteúdos escolhidos. Não é somente trabalhar com as novas tecnologias visando à inclusão digital dos alunos, mas é preciso que a escola as integre nas atividades curriculares, ou seja, integrá-las ao processo de ensino e aprendizagem.

Integrar as TIC na escola vai além de usá-las apenas como ferramentas. Hoje as TIC se configuram em uma nova forma de linguagem, essencial para a representação do conhecimento e, nesse caso, sua presença no currículo escolar é fundamental.

Pela análise feita do Projeto Político Pedagógico constatamos que a escola estudada tem uma preocupação em fazer uso das TIC no processo de ensino e aprendizagem, o que caracteriza uma conscientização da importância das tecnologias na educação hoje, porém não descreve formas de integrá-las curricularmente.

Portanto, a educação para o século XXI necessita de bases que a configure para um contexto atual dinâmico e, desse modo, é preciso rever a estrutura curricular e 
formativa da escola junto a real demanda social, ou seja, não basta equipar as escolas com equipamentos tecnológicos sem antes preparar os profissionais para que de fato os "aceitem" e os utilizem em prol do desenvolvimento e avanço da educação.

\section{THE INTEGRATION OF INFORMATION AND COMMUNICATION TECHNOLOGIES IN SCHOOLS: THE POLITICAL PEDAGOGICAL PROJECT IN THIS CONTEXT}

ABSTRACT: This study aims to analyze the possibilities of integration of new information and communication technologies (ICT) in teaching and learning in a school of public elementary school Municipal Araraquara. This is a survey based on a qualitative approach, which has a strategy Case Study. Made an analysis of the Curriculum Guidelines and Policy Project (PPP) school selected, in order to check how the school addresses the issue of the use of new technologies in the educational process. For the analysis of the Curriculum Guidelines and Educational Policy Project found that the school has studied a concern to make use of ICT in teaching and learning, featuring an awareness of the importance of technology in education, but does not describe ways to integrate curricularmente them. The integration of new technologies into the curriculum requires a systematic reflection about their goals, their technical and content chosen. Not only is working with new technologies aimed at digital inclusion of students, but we need to integrate the school into their curricular, integrate them into the process of teaching and learning. Today ICT configure themselves into a new form of language, essential for knowledge representation and, if so, their presence in the school curriculum is crucial.

KEYWORDS: Information and Communication Technologies. Education. Learning. Political Pedagogical Project.

\section{REFERÊNCIAS}

CASTELLS, M. A sociedade em rede. v.1. São Paulo: Paz e Terra, 1999.

COLL, C.; ILLERA, J. L. R. Alfabetização, novas alfabetizações e alfabetização digital: as TIC no currículo escolar. In: COLL, C.,; MONERO, C. (Org.). Psicologia da educação virtual: aprender e ensinar com as tecnologias da informação e da comunicação. Porto Alegre: Artmed, 2010.

COSTA, R. A cultura digital. São Paulo: Publifolha, 2003.

DENZIN, N. K.; LINCOLN, Y. S. The SAGE handbook of qualitative research. Thousand Oaks, CA: SAGE Publications, 2005.

GENTILINI, J. A. Computadores, informática e educação: questões sobre a gestão de programas de inclusão digital no Brasil. In: VALLE, L. E. L. R do; MATTOS, M. J. V. M.; COSTA, J. W. da (Org.). Educação digital: a tecnologia a favor da inclusão. Porto Alegre: Penso, 2013. 
GIMENO SACRISTÁN, J. Educar e conviver na cultura global: as exigências da cidadania. Porto Alegre: Artmed, 2002.

LEMES, S.S.; RIBEIRO, R. A questão da escolarização enquanto um processo educativo complexo e o necessário apoio tecnológico: algumas pistas de sua dimensão para entendimento e reflexões. In: SOUZA, C. B. G.; RIBEIRO, P. R.M. Desafios educacionais para o século XXI: contribuições dos contextos espanhol e brasileiro. Araraquara: Laboratório Editorial FCL UNESP, 2010.

LEMES, S. S. O pluralismo cultural no processo de escolarização: algumas reflexões sobre certos embates. In: COLVARA, L. D. (Coord.). Cadernos de formação: formação de professores. Bloco 03: Gestão Escolar. São Paulo: Cultura Acadêmica, 2013. Disponível em:

<http://www.acervodigital.unesp.br/bitstream/123456789/65803/4/u1_d29_v3_caderno. pdf>. Acesso em: 28 mai. 2014.

LÈVY, P. Cibercultura. São Paulo: Ed. 34, 1999.

As tecnologias da inteligência: o futuro do pensamento na era da informática. Rio de Janeiro: Ed. 34, 1993.

MARCELO, C. Las tecnologias para la innovación y la práctica docente. Revista Brasileira de Educação, Rio de Janeiro, v.18, n.52, p.25-47, jan./mar. 2013.

Disponível em: <http://www.scielo.br/pdf/rbedu/v18n52/03.pdf〉. Acesso em: 28 mai. 2014.

PASINATO, N. M. B.; VOSGERAU, D. S.R. Proposta para avaliação dos estágios de integração das TIC na escola. In: CONGRESSO NACIONAL DE EDUCAÇÃO, 2011, Curitiba. Anais eletrônicos... Curitiba: PUCPR, 2011. Disponível em:

<www.educere.bruc.com.br/CD2011/pdf/6451_3806.pdf >. Acesso em: 28 mai. 2014.

POZO, J. I. A sociedade da aprendizagem e o desafio de converter informação em conhecimento. Revista Pátio, Porto Alegre, v.8, p.34-36, ago./out. 2004. Disponível em: <www.udemo.org.br/A\%20sociedade.pdf>. Acesso em: 28 mai. 2014.

SÁNCHEZ, J. H. Integración curricular de las TICs: conceptos e ideas. In: CONGRESSO IBERO-AMERICANO DE INFORMÁTICA EDUCATIVA, 6., 2002, Vigo. Anais eletrônicos... Vigo: RiBiE, 2002. Disponível em:

<http://lsm.dei.uc.pt/ribie/docfiles/txt2003729191130paper-325.pdf>. Acesso em: 28 mai. 2014.

SESI. Referenciais curriculares da rede escolar SESI-SP. São Paulo: SESI, 2003.

VEIGA, I. A. Escola: espaço do projeto político-pedagógico. Campinas: Papirus, 1998.

VIEIRA, M. C. A. Gestão escolar e as tecnologias da informação e comunicação: análise das percepções de diretores escolares para ao trabalho com as TICs. 2007. 132f. Dissertação (Mestrado em Educação) - Faculdade de Educação, Universidade Estadual de Campinas, Campinas, 2007. 
VOSGERAU, D. S. R. A tecnologia nas escolas: o papel do gestor neste processo. In: BARBOSA, A. F. (Coord.). Pesquisa sobre o uso das tecnologias de informação e comunicação nas escolas brasileiras: TIC Educação 2011. São Paulo: Comitê Gestor da Internet no Brasil, 2012. Disponível em: <http://op.ceptro.br/cgi-bin/cetic/ticeducacao-2011.pdf >. Acesso em: 28 mai. 2014.

YIN, R. K. Estudo de caso: planejamento e métodos. 2.ed. Porto Alegre: Bookman, 2001. 